\title{
Pengaruh Gaya Kepemimpinan Kristen Pelayan Tuhan Terhadap Pencapaian Hasil Program Kerja Di GKII Jemaat Rhema Makassar
}

\author{
James Wesley Banatau, Hengki Wijaya
}

\begin{abstract}
Abstrak
Kepemimpinan adalah salah satu kesuksesan kerja. Pemimpin sangat diperlukan dalam sebuah organisasi yang dijalankan. Setiap pemimpin memiliki gayanya masing-masing. Diantaranya adalah: gaya kepemimpinan rohani, kepemimpinan hamba, dan gaya kepemimpinan transformatif. Karya ilmiah ini berusaha menggali sejauh mana pengaruh gaya kepemimpinan Kristen pelayan Tuhan terhadap pencapaian hasil program kerja Gereja Kemah Injil Indonesia jemaat Rhema Makassar. Adapun simpulan utama dari hasil penelitian ini adalah: Pertama, Setiap pemimpin memiliki gayanya tersendiri. Beberapa gaya kepemimpinan pelayan Tuhan diantaranya, gaya kepemimpinan rohani, gaya kepemimpinan hamba, dan gaya kepemimpinan transformatif. Gaya kepemimpinan rohani ialah suatu percampuran antara kualitas alamiah dan rohani dari setiap orang yang melayani Tuhan untuk kemuliaan-Nya. Kedua, Program kerja GKII Jemaat Rhema Makassar difokuskan pada ibadah, baik ibadah umum, ibadah organ dan ibadah doa. Selain itu secara rutin dilaksanakan perkunjungan kepada anggota-anggota jemaat, serta mengiuti kegiatankegiatan yang dilaksanakan oleh Badan pengurus GKII Daerah I Makassar. Ketiga, pelayan Tuhan GKII Rhema mencerminkan kepemimpinan Kristen Namun gaya kepemimpinannya itu dominan ialah gaya kepemimpinan Rohani. Keempat, Gaya kepemimpinan memiliki pengaruh dalam tercapainya pelaksanaan program kerja dalam jemaat, apabila program kerja memiliki tujuan dan sasaran jelas dengan meningkatkan keterlibatan aktif jemaat dalam pelaksanaan progam.Kelima, gaya kepemimpinan Kristen berpengaruh terhadap pencapaian hasil program kerja GKII Rhema ditandai dengan persepsi jemaat terhadap hasil program kerja GKII jemaat Rhema yang terkategori baik.
\end{abstract}

Kata-kata Kunci: Pengaruh, Pemimpin, Gaya Kepemimpinan, Program Kerja, GKII Rhema Makassar.

\section{Pendahuluan}

\section{Latar Belakang Masalah}

Sepanjang zaman ini masalah yang sering timbul dan yang terjadi adalah orang semakin sering berbicara tentang masalah kepemimpinan sebagai salah satu kesuksesan kerja. Tidak diragukan lagi bahwa kepemimpinan sangat diperlukan dalam sebuah organisasi yang dijalankan. Hal yang penting ialah seorang pemimpin harus mempunyai 
kemampuan memimpin, tentunya hal ini harus didukung dengan pengalaman sebagai seorang pemimpin.

Dalam Kamus Umum Bahasa Indonesia kata "kepemimpinan" berasal dari kata dasar "pemimpin" yang artinya orang yang memimpin. ${ }^{1}$ Jadi sangat penting dimana setiap orang dapat memiliki kemampuan dalam memimpin. Dalam hal ini kepemimpinan diperoleh dari setiap pengalaman hidup yang menuntun kita untuk terus belajar dan dibentuk. Kepemimpinan sendiri merupakan kegiatan sentral di dalam sebuah kelompok ( organisasi ), dan seorang pemimpin sebagai figur sentral yang memiliki wewenang dan tanggung jawab dalam mengefektifkan organisasi untuk mencapai tujuannya.

Bila melihat kepemimpinan pelayan Tuhan dalam gereja, maka tentu harus bisa dilihat apakah ada karakter sebagai seorang pemimpin dalam diri setiap pelayan Tuhan yang mampu untuk tampil sebagai pemimpin dalam bidang pelayanan tertentu. Kepemimpinan untuk tujuan organisasi tidak hanya bagi kepentingan orang banyak dan secara pribadi tidak hanya melihat kepada laki-laki saja tetapi juga perempuan yang memiliki kemampuan sebagai pemimpin. Dengan demikian seorang pemimpin haruslah memiliki kemampuan dan tujuan yang sama yaitu memiliki karakter atau ciri khas yang mampu memimpin sebuah organisasi tertentu. Tetapi akibat perubahan dewasa ini, muncul juga persoalan lain yang sering dihadapi oleh seorang pemimpin umum atau gereja. Seringkali seorang pemimpin merasa dirinya hebat, dan merasa bahwa ia tidak memerlukan lagi orang lain. Padahal mereka sesungguhnya sangat membutuhkannya. Pemimpin itu ingin menjadi orang yang luar biasa secara cepat atau instan. Ada juga motivasi dari pemimpin tersebut berpusat pada dirinya dan pada keinginannya untuk berkuasa.

Yakob Tomatala berkata tentang kepemimpinan Kristen adalah:

Suatu proses terencana yang dinamis dalam konteks pelayanan Kristen (yang menyangkut faktor waktu, tempat, dan situasi khusus) yang didalamnya oleh campur tangan Allah, Ia memanggil bagi diri-Nya seorang pemimpin (dengan kapasitas penuh) untuk memimpin umat-Nya (dalam pengelompokan diri sebagai suatu institusi/organisasi) guna mencapai tujuan Allah (yang membawa keuntungan bagi pemimpin,bawahan, dan lingkungan hidup) bagi dan melalui umat-Nya, untuk kejayaan Kerajaan-Nya. ${ }^{2}$

Pemimpin dalam bidang pelayanan tentunya harus bisa memberikan pengaruh bagi orang lain dan bagi orang-orang yang dipimpin. Ketika seseorang telah dipilih untuk menjadi seorang pemimpin tentu saja orang tersebut harus bertanggung jawab dalam menjalankan tugas yang dipimpinnya dengan baik. Dengan demikian, seorang pemimpin harus sanggup menjalankan tugasnya secara baik, dengan lebih mengutamakan kesejahtraan orang lain tanpa memikirkan dirinya sendiri, disiplin, dan memiliki semangat yang kuat atau memiliki komitmen yang kuat dan mampu secara terbuka menerima masukan, kritikan atau nasihat dari orang lain. ${ }^{3}$

Kepemimpinan merupakan kegiatan sentral dalam sebuah kelompok ( organisasi ), dan seorang pemimpin puncak sebagai figur sentral menyandang peran mempersatukan anggota organisasi yang terdiri dari individu-individu, agar menjadi satu kesatuan kekuatan yang bergerak ke arah yang sama. Kepemimpinan memiliki kedudukan dan posisi yang

\footnotetext{
${ }^{1}$ W. J. S. Poerwadarminta, Kamus Umum Bahasa Indonesia (Jakarta: Balai Pustaka, 1986), 729, s.v. "Pemimpin".

${ }^{2}$ Yakob Tomatala, Kepemimpinan Yang Dinamis (Jakarta: YT Leadership Foundation, 1997), 43.

${ }^{3}$ J. Oswald Sanders, Kepemimpinan Rohani (Bandung: Kalam Hidup, 1979), 125.
} 
sangat penting dan utama dalam menentukan berbagai aspek dalam kehidupan organisasinya. Daripada itu juga diperlukan pengendalian dalam kepemimpinan, pengendalian dalam kepemimpinan dilaksanakan untuk memberdayakan semua dan setiap anggota agar organisasi secara keseluruhan dapat berjalan secara efektif dalam mencapai tujuannya.

Seiring berjalannya waktu sampai sekaranga ini masih terus dipersoalkan mengenai orang yang mampu melaksanakan kepemimpinan atau siapa pemimpin itu, apa tipe atau gaya kepemimpinan yang efektif, atau bagaimana pelaksanaan kepemimpinan yang efektif. Berbagai teori kepemimpinan dengan maksud untuk memberikan gambaran mengenai perkembangan dan pemahaman mengenai kepemimpinan untuk mengefektifkan organisasi dalam mencapai tujuannya, teori tersebut antara lain: Teori Great Man dan Teori Big Bang, Teori Sifat atau karakteristik kepribadian (Trait Theories), Teori Perilaku (Behavior theories). Teori Great Man dan Big Bang itu sendiri memiliki pengertian bahwa seorang pemimpin dilahirkan bukan diciptakan dan lewat suatu peristiwa besar mampu menciptakan sebuah pemimpin besar, sedangkan teori sifat atau karakteristik menyatakan bahwa seorang dapat menjadi pemimpin apabila memiliki sifat-sifat kepribadian yang dibutuhkan seorang pemimpin, teori perilaku ini sangat memusatkan perhatiannya pada fungsi-fungsi kepemimpinan. ${ }^{4}$

Hal yang sering terjadi dalam kepemimpinan itu sendiri sering terjadinya penyimpangan yang terjadi dalam kepemimpinan. Hal yang menyebabkan terjadinya hal tersebut disebabkan oleh kurangnya kecerdasan intelektual seorang pemimpin. Kecerdasan intelektual sangat dibutuhkan oleh setiap pemimpin untuk dapat menyelesaikan masalahmasalah yang terjadi. Disamping itu juga penyimpangan yang terjadi dalam sebuah pemimpin yaitu kurang memiliki keterampilan untuk mengerjakan sesuatu, sehingga banyak hal yang membuat seorang pemimpin tidak bisa mencapai sasaran yang ingin dicapai. Dengan demikian sangatlah penting kepemimpinan dalam gereja agar para pemimpin mampu menghubungkan kembali eklesiologi dan misiologi dengan demikian gereja didefinisikan pertama dan terutama oleh misi yang diberikan Allah.

Berdasarkan pengamatan yang dilakukan oleh penulis banyak ditemukan pelbagai hal yang dilakukan dengan cara yang tidak benar dalam menentukan berbagai pemimpin pelayan Tuhan di berbagai sektor pelayanan yang terjadi dalam gereja. Mengapa penulis mengambil sebuah penelitian di dalam gereja karena banyak posisi seorang pemimpin pelayan Tuhan tidak mampu untuk memimpin tugas dan fungsinya dengan baik sehingga pelayanan yang dilakukan tidak sesuai dengan tujuan yang ingin dicapai karena memimpin dengan hati gembala adalah tentang melayani, menuntun, mengarahkan, menantang, danmembantu orang lain dan untuk bertumbuh. Kepemimpinan gembala tidak menyangkut soal aktivitas manajemen namun menumbuhkan orang yang kita pimpin. ${ }^{5}$

Melihat hal tersebut membuat saya menilai bahwa kondisi yang terjadi dalam gereja ini sangatlah memprihatinkan karena kondisi seperti ini sangat mengganggu program yang ada dalam jemaat, terlebih dari semuanya itu masalah krisis kepemimpinan sangat terasa terjadi dalam jemaat ini.

\footnotetext{
${ }^{4}$ Hadari Nawawi, Kepemimpinan Mengefektifkan Organisasi (Yogyakarta:Gadjah Mada, 2003), 73

${ }^{5}$ Daniel Ronda, “Kepemimpinan Model Gembala," Jurnal Jaffray 7, No. 2 (Oktober 2009): 18, diakses 22 Februari 2017, http://ojs.sttjaffray.ac.id/index.php/jjv71/article/view/28/pdf_18
} 
Tetapi ada juga yang tidak mempunyai ciri-ciri tersebut tapi mampu untuk menjadi seorang pemimpin. Contoh kepemimpinan tersebut ialah pemimpin yang mampu mengayomi, melindungi, bersemangat tetapi ada juga pemimpin yang memerintah secara otoriter, demokratis.

Salah satu contoh pemimpin yang dapat dicontoh ialah Tuhan Yesus yang melayani. Dalam kitab Matius 20:28 "sama seperti anak manusia datang bukan untuk dilayani, melainkan untuk melayani dan untuk memberikan nyawa-Nya menjadi tebusan bagi orang banyak". Artinya bahwa kita sebagai pemimpin harus bisa menjadi seorang yang mampu untuk mempengaruhiantar pribadi atau antar orang dalam suatu situasi tertentu melalui aktivitas komunikasi yang terarah untuk mencapai suatu tujuan atau tujuan-tujuan tertentu.Dalam kepemimpinan selalu terdapat unsur pemimpin (influencee), yakni yang mempengaruhi tingkah laku pengikutnya (influencer) atau para pengikutnya dalam suatu situasi yang ada. ${ }^{6}$

Dalam banyak faktor yang mempengaruhi gereja hal ini di sebabkan oleh karena kurangnya pemahaman akan kesadaran dari pemimpin itu sendiri ataupun di sebabkan oleh kesombongan dan merasa lebih dari yang lain dan yang dipimpinnya bahkan merasa mampu dalam memimpin. ${ }^{7}$ Fakta yang terjadi saat ini masih banyak pemimpin yang mengalami banyak masalah dalam menjadi seorang pemimpin. Suka dan duka pun menjadi bagian dalam menjalani tugas tersebut.

\section{Pokok Masalah}

Berdasarkan latar belakang di atas maka pokok masalah dalam penulisan skripsi ini adalah sejauh mana pengaruh gaya kepemimpinan Kristen pelayan Tuhan terhadap pencapaian hasil program kerja Gereja Kemah Injil Indonesia jemaat Rhema Makassar ?.

\section{Tujuan Penelitian}

Adapun tujuan dalam penulisan skripsi ini adalah untuk mengetahui pengaruh gaya kepemimpinan kristen pelayanan Tuhan terhadap pencapaian program kerja Gereja Kemah Injil Indonesia jemaat Rhema Makassar.

\section{Manfaat Penelitian}

Pertama, tulisan karya ilmiah ini dapat menjadi bahan bacaan yang dapat menambah wawasan bagi penulisan, lembaga, akademik, gereja, dan pekerja.

Kedua, agar pelayan Tuhan mengerti pentingnya gaya kepemimpinan Kristen untuk meningkatkan pelayanan di gereja.

Ketiga, bahan masukan bagi pembaca dan mahasiswa Sekolah Tinggi Theologia Jaffray Makassar

Keempat, untuk memenuhi salah satu persyaratan akademik dalam mencapai gelar Sarjana Teologi di Sekolah Tinggi Theologia Jaffray Makassar.

${ }^{6}$ Jermia Djadi, “Kepemimpinan yang Efektif,” Jurnal Jaffray 7, No. 1 (2009): 16, diakses 22 februari 2017,http://ojs.sttjaffray.ac.id/index.php/jjv71/article/view/5/pdf_3

${ }^{7}$ Ferry Pigai, "Analisis Ciri Kepemimpinan Hamba Serta Relevansinya Pada Masa Kini Berdasarkan Injil Matius 20:26-28," Jurnal Jaffray 11, no 1 (April2013), diakses 22 Februari

2017,http://ojs.sttjaffray.ac.id/index.php/jjv71/article/view/76 


\section{Metode Penelitian}

Adapun penulisan skripsi ini, penulis menggunakan metode penelitian kuantitatif dan kualitatif dengan menggunakan pedoman pengumpulan data melalui angket dan bukubuku sebagai literatur dan tulisan-tulisan di media online yang berhubungan dengan pembahasan dalam skripsi. ${ }^{8}$

\section{Batasan Penelitian}

Penulisan ini membahas makna dari gaya kepemimpinan pelayan Tuhan terhadap pencapaian hasil kerja program gereja. Dan penulis membatasi penulisan ini dengan berfokus pada satu gereja, yaitu Gereja Kemah Injil Indonesia Jemaat Rhema Makassar.

\section{Kesimpulan}

Kesimpulan dari keseluruhan karya ilmiah ini adalah:

Pertama, Setiap pemimpin memiliki gayanya tersendiri. Beberapa gaya kepemimpinan pelayan Tuhan diantaranya,gaya kepemimpinan rohani, gaya kepemimpinan hamba, dan gaya kepemimpinan transformatif. Gaya kepemimpinan rohani ialah suatu percampuran antara kualitas alamiah dan rohani dari setiap orang yang melayani Tuhan untuk kemuliaan-Nya.

Kedua, Program kerja GKII Jemaat Rhema Makassar difokuskan pada ibadah, baik ibadah umum, ibadah organ dan ibadah doa. Selain itu secara rutin dilaksanakan perkunjungan kepada anggota-anggota jemaat, serta mengiuti kegiatan-kegiatan yang dilaksanakan oleh Badan pengurus GKII Daerah I Makassar.

Ketiga, pelayan Tuhan GKII Rhema mencerminkan kepemimpinan kristen Namun gaya kepemimpinannya itu dominan ialah gaya kepemimpinan Rohani.

Keempat, Gaya kepemimpinan memiliki pengaruh dalam tercapainya pelaksanaan program kerja dalam jemaat, apabila program kerja memiliki tujuan dan sasaran jelas dengan meningkatkan keterlibatan aktif jemaat dalam pelaksanaan progam.

Kelima, gaya kepemimpinan Kristen berpengaruh terhadap pencapaian hasil program kerja GKII Rhema ditandai dengan persepsi jemaat terhadap hasil program kerja GKII jemaat Rhema yang terkategori baik.

\section{Kepustakaan}

Chandra, Robby I. Kaти Juga Bisa Kenal. Jakarta: YLI, 2009.

Chandra, Robby I. Ketika Pemimpin Harus Menghadapi Perubahan. Bandung: Bina Media Informasi, 2005.

Clinton, J. Robert. Pembentukan Pemimpin Sejati. Anaheim, Ca.: Church Resource Ministries CRM, 2004.

Cribbin, James J. Kepemimpinan Strategi Mengefektifkan Organisasi. Jakarta: Pustaka Binaman Pressindo, 1982.

\footnotetext{
${ }^{8}$ Hengki Wijaya, Analisis Data Kualitatif Ilmu Pendidikan Teologi (Makassar: Sekolah Tinggi Theologia Jaffray Makassar, 2016).
} 
Djadi, Jermia. “Kepemimpinan yang Efektif .” Jurnal Jaffray 7, No. 1 (2009):16-17.

Diakses 22 Februari 2017.

http://ojs.sttjaffray.ac.id/index.php/jjv71/article/view/5/pdf_3.

Griffiths, Michael. Gereja dan Panggilannya Dewasa Ini. Jakarta: BPK Gunung Mulia, 1991.

Hocking, David. Rahasia Keberhasilan Seorang Pemimpin. Yogyakarta: ANDI, 2003.

Hutagalung, Sutan M. Identitas Kepemimpinan Pelayan Gereja. Jakarta: BPK Gunung Mulia, 1997.

Kartono, Kartini. Pemimpin dan Kepemimpinan. Jakarta: Rajawali, 1986.

Lewis, Rodger. Karya Kristus di Indonesia. Bandung: Kalam Hidup, 2007.

MacArthur, John. Kitab Kepemimpinan. Jakarta; BPK Gunung Mulia, 2011.

Maxwell, John C. Semua Orang Bisa Memimpin. Jakarta: BPK Gunung Mulia, 2014.

Nawawi, Hadari dan M. Martini Nawawi. Kepemimpinan Yang Efektif. Yogyakarta: Gajah Mada University Press, 2005.

Pigai, Ferry. "Analisis Ciri Kepemimpinan Hamba Serta Relevansinya Pada Masa Kini Berdasarkan Injil Matius 20:26-28." Jurnal Jaffray 11, no 1 ( April 2013): 176-198. Diakses: 22 Februari 2017. http://ojs.sttjaffray.ac.id/index.php/jjv71/article/view/76

Ronda, Daniel. Kepemimpinan Kristen. Makassar: Sekolah Tinggi Theologia Jaffray, 2010. Belum dipublikasikan

Ronda, Daniel. "Kepemimpinan Model Gembala.” Jurnal Jaffray 7, No. 2 (Oktober 2009): 56-63. http://ojs.sttjaffray.ac.id/index.php/jjv71/ article/view/28/pdf_18

Sanders, J. Oswald. Kepemimpinan Rohani. Bandung: Kalam Hidup, 1979.

Sinamo, Jansen. 8 Etos Kerja Profesional. Bandung: Bimas Kristen, 2012 .

Smith, Fred. Memimpin Dengan Integritas Jakarta: Imanuel, 2002.

Subagyo, Andreas B. Pengantar Riset Kuantitatif dan Kualitatif. Bandung: Yayasan Kalam Hidup, 2004.

Tidball, Derek J. Teologi Penggembalaan. Jakarta: Yayasan Gandum Mas, 1995.

Tomatala, Yakob. Kepemimpinan Yang Dinamis. Jakarta: YT Leadership Foundation, 1997. Kepemimpinan Kristen. Jakarta: YT Leadership Foundation, 2002. . Pemimpin Yang Handal. Jakarta: YT Leadership Foundation, 1996. Manusia Sukses Jakarta: YL leadership Foundation, 1998.

Tu'u, Tulus. Pemimpin Kristiani Yang Berhasil, Vol. 1. Bandung: Bina Media Informasi, 2010.

Ukas, Maman. Manajemen: Prinsip dan Aplikasi. Bandung: Agnini, 2004.

Usman, Husaini. Metodologi Penelitian Sosial. Jakarta: Bumi Aksara, 1996.

Widjaja, Raymondus Indra. "Implementasi Karakter Pemimpin Kristen di CV. Suma Gemilang,"AGORA 3, no. 1 (2015): 121-131

White, John. Pemimpin Yang Handal. Bandung:Yayasan Kalam Hidup, 1994.

Wijaya, H. Analisis Data Kualitatif Ilmu Pendidikan Teologi. Makassar: Sekolah Tinggi Theologia Jaffray, 2018.

Wijaya, Hengki (ed.). Metodologi Penelitian Pendidikan Teologi. Makassar: Sekolah Tinggi Theologia Jaffray, 2016. 
